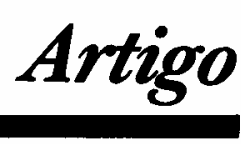

1. Introdução;

2. A questão das metáforas em marketing;

3. A metáfora da soberania do consumidor;

4. A dependência da realidade do consumo;

5. Discussão e conclusão.

\section{$A$ metáfora da soberania do consumidor e suas implicações para o conceito de marketing}

Paulo Cesar Motta

Protessor de marketing e estratégia empresarial e diretor do Departamento de Administraçáo da PUC/RJ

\section{INTRODUÇÃO}

Durante algum tempo, a filosofia gerenciąl característica do conceito de marketing parece ter sido aceita sem reservas. Contudo, cerca de uma década após sua formulaçãa, ${ }^{1}$ teve início uma polêmica que parece ainda náo se ter esgotado. Críticas de natureza diversa têm sido freqüentemente formuladas contra essa filosofia. Entre elas, as que alegam um completo desprezo, na atividade de marketing, pelas causas sociais, ${ }^{2}$ dependência contextual, ${ }^{3}$ responsabilidade por perdas competitivas a longo prazo, ${ }^{4}$ além da emergente acusação de que o conceito de marketing não se aplica a duas classes distintas de produtores: os artistas $\theta$ os ideólogos. ${ }^{5}$

A maior parte dessa polêmica, porém, deu-se no domínio da aplicabilidade, com pouco espaço sendo dedicado à filosofia que o conceito encerra. Em sua formulação mais tradicional, o conceito de marketing pressupōe que o conhecimento das caracteristicas do consumidor deva sempre preceder qualquer esforço do produtor dirigido à satisfação da necessidade de consumo. Todavia, desde que a troca passou a ser considerada como a idéia central deste processo,' o conceito de marketing vem sendo repensado sob novas perspectivas.

Desse modo, o objetivo deste artigo é discutir, a partir de uma estrutura conceitual, as crificas que têm sido ou poderão ser dirigidas ao conceito de marketing, que será tratado não apenas como orientador dos processos gerenciais - o que tem sido facilmente absorvido - mas também como um processo social - o que tem sido normalmente esquecido. ${ }^{\circ} \mathrm{E}$, sobretudo, chamar a atenção para dois aspectos adicionais:

a) a inflexível adesão dos que vêem o conceito como orientador dos procesșos gerenciais; $e$

b) a pressuposiçáo de que o conceito possui uma significativa capacidade heuristica quanto à dimensão de consumo, vista de uma maneira genérica no processo social.

$A$ abordagem dessas questōes obedece a um ènfoque que realça tanto a presença como a dependência de metáforas, particularmente na construção do conceito de orientação para o mercado. Aliás, o próprio conceito de marketing pode ser considerado uma metáfora, ' baseada, possivelmente, na idéia de uma relação próxima, ou até mesmo intima, entre consumidores e organizaçōes. Deste relacionamento, derivam-se implicaçōes filosóficas, estratégicas operacionais e, principalmente, o uso de uma outra metáfora: a da soberania do consumidor.

\section{A QUESTÃO DAS METÁFORAS EM MARKETING}

A metáfora é uma forma algo rudimentar de se alcançar algum conhecimento sobre o desconhecido. ${ }^{10}$ Implica comparações que, feitas de maneira adequada, podem provocar a expansão do conhecimento, facilitar a comunicação, auxiliar na geração de idéias e jogar luz sobre fenơmenos comportamentais. A abundância de metáforas em marketing aponta notoriamente para o papel que são 
chamadas a desempenhar na construção dos conceitos necessários à expansão da ciência do marketing.

Todavia, quando se procede a uma análise mais cuidadosa do conceito que deu origem à metáfora, fica evidente que, a par de facilitação do conhecimento, podem ocorrer também certas modificaçōes de sentido, como será discutido mais adiante, ao se considerar a metáfora da soberania do consumidor.

Ao traçar-se a origem das metáforas em marketing constata-se que as relaçōes entre o mundo físico e as pessoas, como assinalou Rosenberg," estão por trás de quase todas elas, embora se assentem em bases variadas (que podem ser múltiplas) e o sentido que adquirem seja função direta da experiência e visão de mundo de quem as cria. O quadro I fornece alguns exemplos neste sentido.

\begin{tabular}{|ll|}
\multicolumn{2}{|c|}{ Quadro I } \\
\multicolumn{1}{c|}{ Exemplos de metáforas em marketing } \\
\hline \multicolumn{1}{c|}{ Conceito } & \multicolumn{1}{c|}{ Base } \\
\hline Canibalismo do produto & Antropologia \\
Venda missionária & Religið̊o \\
Imagem & Arte, psicologia \\
Canal de distribuiç̧o & Geografia \\
Atratividade do mercado & Sexo \\
Miopia em marketing & Medicina \\
\hline
\end{tabular}

As metáforas encerram um problema de conjugação de realidades objetivas com realidades subjetivas. Como se interpretaria, por exemplo, canibalizar o produto ou fazer venda missionária? Vê-se, portanto, que, embora ajudem na aquisição do conhecimento por meio de analogias, muitas vezes subjetivas, com outros conceitos, se tomadas objetivamente, em sentido literal, nada significariam.

Aparentemente, as metáforas são criadas não só para facilitar a aquisição de conhecimento, como também para facilitar a incursão nas relações e conexões dos elementos produzidos pr: elas. Assim, quando se fala do ciclo de vida do produto, relaçōes entre produtos e mercados podem ser explicitadas por meio de analogias com a mecânica dos ciclos e a evolução da vida.

Finalmente, cabe observar que o conceito que se introjeta nem sempre se traduz numa só metáfora. Esta, por sua vez, denota sempre um único aspecto. Conseqüentemente, torna-se necessário criar outras para descrever melhor todas as relações ou fenômenos que se julga estarem relacionados ao conceito. Assim, o conceito de mercado acabou dando origem a diversas outras metáforas, como as da penetração, crescimento, orquestração, erosão, saturação, parcela e outras mais.

\section{A METÁFORA DA SOBERANIA DO CONSUMIDOR}

Não resta dúvida de que o termo soberania tem a agradabilidade $\theta$ a atratividade ideais para a construção de uma metáfora. Não obstante, a construção metafórica da soberania do consumidor peca pela incapacidade de expressar um conceito, embora náo deixe de trazer consigo um conjunto de conhecimentos adicionais indutiveis a partir do próprio apelo semântico.

Com efeito, é provável que a aceitaçāo generalizada do conceito de marketing, advenha mais de sua capacidade de causar impressóes agradáveis do que dos aspectos teóricos descritivos que lhe deram origem. A agradabilidade decorre da ênfase no atendimento das necessidades do consumidor - um renovado romance com o nostálgico princípio da soberania do consumidor mais todas ás implicações de simplicidade e sujeição que as metáforas são capazes de produzir.

A crença na soberania do consumidor implica, na maioria das vezes, atribuir-lhe poder de escolha, enquanto que a descrença leva a atribuição do poder de escolha ao outro lado. Este processo se torna relevante na medida em que propicia livre curso a certas ideologias. Assim, quando se acredita nessa soberania, tende-se a favorecer a soluçăo das questóes sociais pelo financiamento dos consumidores, e quando não se acredita, pelo financiamento dos produtores. Desse modo, as imagens, transferidas da "soberania" do governo para a "soberania" do consumidor sāo logicamente moldadas em funçāo de conotaçð̋es ideológicas pertinentes.

A crença na soberania do consumidor envolve uma estruturação metafórica na qual se incluem a orientaçāo para o mercado e o sucesso empresarial. Produzem-se, assim, não apenas abundantes exemplos de sucesso, explicados pela boa orientação para o mercado, como também exemplos de fracasso, explicados pela falta dessa orientação. ${ }^{12}$ Na maioria das vezes, é dessa maneira que o sucesso e o fracasso são discriminados, pois, ao não abrir mão das próprias crenças, o indivíduo não só é levado a formular conceitos consonantes com elas, como esses conceitos acabam reforçando as crenças originais.

Quando o consumidor se manifesta no mercado, presume-se que transmita um conjunto notável de instruçōes ao qual as empresas deverão se subordinar. Com isso, faz-se uma vinculação irrestrita entre a soberania do consumidor e o mercado. Como a crença na viabilidade da economia de mercado supōe a crença na soberania do consumidor, ela se segue, necessariamente, à orientação para o mercado. ${ }^{13}$ Por outro lado, se o consumidor não for capaz de produzir as informaçōes necessárias a um bom desempenho do mercado, invertem-se as crenças e o produtor passa a ser considerado como o mais capaz de produzii-las.

Uma simples reflexăo revela que, ao presumir que o consumidor é soberano, acredita-se, inevitavelmente, em sua racionalidade e competência, mesmo não sendo esta uma exigência integrante do conceito de marketing. É preciso considerar o consumidor sábio o bastante para expressar suas necessidades em termos de produtos apropriados, tanto para o presente como para o futuro. E, conseqüentemente, supor que ele seja capaz de transmitir às empresas os elementos essenciais para uma orientação adequada no que se refere a investimentos e garantia de posiçőes competitivas a longo prazo. Mas, se o consumi- 
dor for sábio somente ao definir suas necessidades em termos dos seus conhecimentos atuais de produtos $\theta$ mercados, a orientaçāo genérica e de longo prazo não encontra nele a origem que a crença básica pressupōe.

Já se chamou atençăo para o fato de muitos produtos de sucesso não terem sido desenvolvidos com base apenas em seus usuários potenciais: " Apontou-se, também, a incapacidade do consumidor em revelar outras formas de atendimento relativas às suas necessidades, a não ser quando derivadas dos padrōes estabelecidos pelos próprios produtos existentes. ${ }^{18}$

Típico deste posicionamento é a admissão da chamada orientaçāo para produto como sendo algo antagónica (não-complementar) à orientação para o marketing, colocando-a em estágio precedente a esta em um processo de evolução visível, mas de significado questionável.

Um tratamento mais adequado a essas questōes reside na compreensão mais rigorosa das complexidades envolvidas nos processos de troca - enfoque a que o marketing, aderiu recentemente. ${ }^{16} \mathrm{~A}$ troca origina-se tanto na presença como na ausência de elementos de valor num universo de indivíduos e organizaçōes que, por essa razão, podem se envolver num processo de permutas generalizadas. Com tsso, não se pode presumir que certas partes tenham prerrogativas quanto à tomada de iniciativa no processo, o que provavelmente ocorre na metáfora da soberania. $\mathrm{Na}$ abordagem tradicional, resultante da crença subjacente, cabe ao consumidor a iniciativa de se manifestar e ao produtor, a iniciativa de reagir. Tão imbuída ficou a teoria desta forma de pensar que, mesmo após o aparecimento de novos enfoques que enfatizaram o papel da troca, continuou-se presumindo que a ação de marketing é algo que o produtor faz para atender ao consumidor.

Recentemente, Kotler ${ }^{17}$ revelou sua inclinação para uma reformulação da maneira tradicional de encarar o conceito de marketing. Passou a admitir que o processo gerencial deva aplicar-se também ao ambiente e a seus múltiplos públicos, e não somente ao composto de marketing. Recomendações na mesma direçāo, alertando para a necessidade de orientar esforços para alterar as condições ambientais das empresas, também estão presentes em outras fontes da literatura recente. ${ }^{18}$

\section{A DEPENDÉNCIA DA REALIDADE DO CONSUMO}

A crença na soberania do consumidor tem conduzido à dependência da realidade do consumo, isto é, o comportamento do consumidor ao comprar ou não comprar, continuar comprando ou deixar de comprar é que define o mecanismo de punição e recompensa para o produtor. A recompensa tem origem na satisfaçāo do consumidor, medida pelo comportamento de compra atual e sua continuidade, o que redunda em lucro para o produtor. A punição se dá pela rejeição do consumidor, manifestada pela ausência ou descontinuidade de compra, o que resulta em prejuízo para o produtor.

Năo há dúvida de que uma das maiores limitaçóes das metáforas reside na incapacidade que muitas delas têm para expressar todas as dimensőes de um conceito. E o posicionamento acima parece ser um bom exemplo.

A conveniência de se conjugar tanto a crença na soberania do consumidor quanto a satisfaçāo de necessidades com a geração de lucros conduz a uma superficialidade analftica. Como em muitos casos a descrição das condutas observadas mostra-se convincente, o maior aprofundamento do conhecimento dos fenómenos pertinentes é desencorajado. Porquanto isso seja válido para entender alguns aspectos dos comportaméntos envolvidos, nāo é, no entanto, suficiente para explicá-los por completo.

Como em muitas situaçőes, o conhecimento da causa do fenómeno contemplado - o consumo no caso - nāo é importante para a compreensāo do fenômeno observado - a compra, no caso - e pouco se questiona acerca do problema. Na verdade, tal como acontece com qualquer crença 'mais profunda, a tendência é sempre buscar confirmação daquilo em que se acredita. Embora este aspecto possa parecer insignificante, é nele que se encontra o cerne do problema.

A formulação metafórica, ou o uso inadequado das palavras, como acaba de ser demonstrado no caso de "compra" e "consumo", pode impedir a compreensão dos fenômenos subjacentes e, o que é pior, pode gerar crenças ou expectativas falsas. O linguajar diário, até mesmo de órgãos técnicos e de divulgação, reportando a hora de o sol nascer e de se pór, ilustra a questão. A insistência nessa metáfora leva muitos a crerem que o sol realmente nasce e realmente se põe. No caso, a pobreza científica da observação, além de não ajudar a identificar o consumidor satisfeito, também não ajuda a rejeitar a semântica usual, já que o nascer e o pôr-do-sol são o que realmente se observa.

A dificuldade em questionar a semåntica usual acarreta uma concomitante falta de questionamento acerca da natureza dos fenómenos observados e, o que é ainda mais perturbador, leva à produção de circunstâncias que reforçam as crenças tradicionais. É o que se dá quando se relaciona soberania do consumidor a compra e a consumo. Por conseguinte, seria mais enriquecedor procurar distinguir, de maneira mais nitida e independente, os fenómenos formadores da compra (a realidade do consumo) dos feniómenos formadores do consumo (a causa do consumo). Normalmente, as pessoas prendem-se mais à realidade da compra do que à do consumo, questionando bem menos esta do que aquela.

\section{DISCUSSÃO E CONCLUSÃO}

Não é difícil entender a vinculação metafórica que a soberania do consumidor faz entre compra e satisfação. A satisfaçáo é um conceito psicológico, um estado interno dificil de ser mensurado. Em virtude disso, a satisfação pode apresentar um conjunto de dimensões complexas que a tradução metafórica năo consegue captar ou reproduzir. A compra é um fenómeno mais simples, mais observável do que a satisfação postulada pelo conceito de marketing. $\mathrm{Na}$ passagem do desconhecido (satistação) 
para o conhecido (compra), o conhecimento que se ganha é extremamente sacrificado pelo grande hiato que se interpōe entre os dois conceitos.

Alguns podem nāo se dar conta de que se trata de uma metáfora, enquanto que outros, mesmo conscientes da parcialidade da analogia, podem não perceber as diferenças de complexidade na formulação dos dois conceitos. 0 perigo desse tipo de ignoråncia é que pode dar origem a crenças fortes, quase ao nível do pensamento mítico. ${ }^{19} \mathrm{~A}$ vinculação da compra à satisfação do consumidor é, para muitos, uma relação teórica de fácil adesão. Além de não terem consciência de que se trata de uma metáfora, nem mesmo se dão conta de que se trata de uma crença, e a compra continua a ser considerada como a própria maneira de se medir a satisfação. $E$, desse modo, o que era simplesmente um fenômeno interno (crença) passa a ser percebido tão-somente como um fenômeno externo (relação compráçatisfação).

O que se deduz de toda a argumentação acima é que o conceito de orientação para o marketing tem uma formulação que implica relações frơxas, que não resistem a certas pressōes analíticas. Traz consigo uma inércia de premissas, em virtude da formulação metafórica da soberania do consumidor e da orientação para o mercado.

Uma reconceituação da orientação para o marketing deve exigir o desapego a alguns pressupostos e uma visão causal mais abrangente da satisfação das necessidades do consumidor. Sobretudo, deve tirar proveito da troca como uma interação mais ampla e permanente do que o simples ato de compra e venda.

Aparentemente, há na formulação do conceito de marketing uma precipitação em associá-lo ao lucro e à sobrevivência das organizações. Além de desnecessário como premissa científica, um conceito não precisa ter poder preditivo para ter força explicativa. Mesmo que o conceito em questão tivesse algum poder nessa direção, as relações decorrentes seriam um forte obstáculo à conclusão do raciocínio, porque mal estabelecidas. Provavelmente, essa associação teve origem tanto no pensamento cientifico de natureza positivista, como também no apego à crença na soberania do consumidor, na medida em que tal crença reflete um completo desprezo pelo poder que a figura lingüística da metáfora pode ter sobre o raciocínio conceitual.

Em decorrência de tal precipitação, torna-se plausível viabilizar-se a noção de que o marketing, tal como vem sendo tradicionalmente concebido, pode nem levar à sobrevivência das organizações, o que promete, nem permitir que dele se induza a soberania do consumidor, o que postula.
${ }^{1}$ McKiterick, J.B. What is the marketing management concept? In: Frontiers of marketing thought and action. Chicago, American Marketing Association, 1957.

${ }^{2}$ Bell, M.L. e Emory, C.W. The faltering marketing concept, Joumal of Marketing. Chicago, American Marketing Association, 35(4): 37-42, 1971 .

${ }^{3}$ Dholakia, N.; Firat, A. \& Bagozzi, R. The De-americanization of marketing thought in search for a universal basis. In: Lamb, Jr., C.W. \& Dunne, A.M., org. Theoretical development in marketing. Chicago, American Marketing Association, 1980. (Proceedings Series).

${ }^{4}$ Hayes, R.H. \& Albemathy, W.J. Managing our way to economic decline, Harvard Business Review. Cambridge, Harvard University Press, July/Aug. 1980. p. 67-77.

${ }^{5}$ Hirschman, E.C. Aesthetics. Ideologies and the limits of the marketing concept. Joumal of Marketing, 46(3):45-55, 1983.

'Stanton, W.J. Fundamentos de marketing. Sáo Paulo, Pioneira, 1984.

${ }^{7}$ Ver Kotler, P. \& Levy, S. Broadening the concept of marketing. Journal of Marketing, 33(1):10-5, 1969; Tucker, W.T. Future directions in marketing theory. Joumal of Marketing, $38(2): 30-5,1974$; Bagozzi, R. Marketing as exchange. Journal of Marketing, 39(4):32-9, 1975.

${ }^{8}$ Stidsen, B. Comentário sobre: Toward a concept of domesticated markets. Journal of Marketing, 43(4):76-8, 1979.

${ }^{9}$ Rosenberg, L.J. The pervasive role of metaphors in marketing science. Trabalho apresentado à Winter Educators. American Marketing Association, Escola de Administraçáo, University of Massachusetts, 1984. Mimeogr.

${ }^{10}$ As consideraçóes sobre metáforas neste trabalho baseiam-se em Black, M. Models and metaphors - studies in language and philosophy. Cornell University Press, 1962; e em Ortony, A., org. Metaphor and thought. New York, Cambridge University Press, 1979.

${ }^{11}$ Rosenberg, L.J. op. cit.

${ }^{12}$ Levitt, T. Marketing myopia. Harvard Business Review, July/Aug. 1960. Trad. em Biblioteca Harvard. Sáo Paulo, Abril-Tec. v. 1, n. 1.

${ }^{13}$ Stidsen, B. \& Schutte, T.F. Marketing as a communication system: the marketing concept revisited. Journal of Marketing, 36(4): 22-7, 1972.

${ }^{14}$ Burnett, L. Marketing snags and fallacies. Joumal of Marketing, 30(3): $1-5,1966$.

${ }^{15}$ Hall, W.K. Survival strategies in a hostile environment. Harvard Business Review, p. 75-85, Sept./Oct. 1980.

${ }^{16}$ Motta, P.C. Marketing: a extinçăo de uma disciplina. Revista de Administraçáo, São Paulo, USP, 18(1), 1983.

${ }^{17}$ Ver Kotler: Rethink the marketing concept. Entrevista concedida por P. Kotler à revista Marketing News, 18(19), 1984.

${ }^{18}$ Zeithaml, V. \& Zeithaml. Environment management revising the marketing perspective. Journal of Marketing, 48(2):45-53, 1984.

${ }^{19}$ Zikmund, W.G. Metaphors as methodology. In: Busch, R.F. \& Hunt, S.D., org. Marketing theory: philosophy of science perspective. Chicago, American Marketing Association, 1982. (Proceedings Series.)

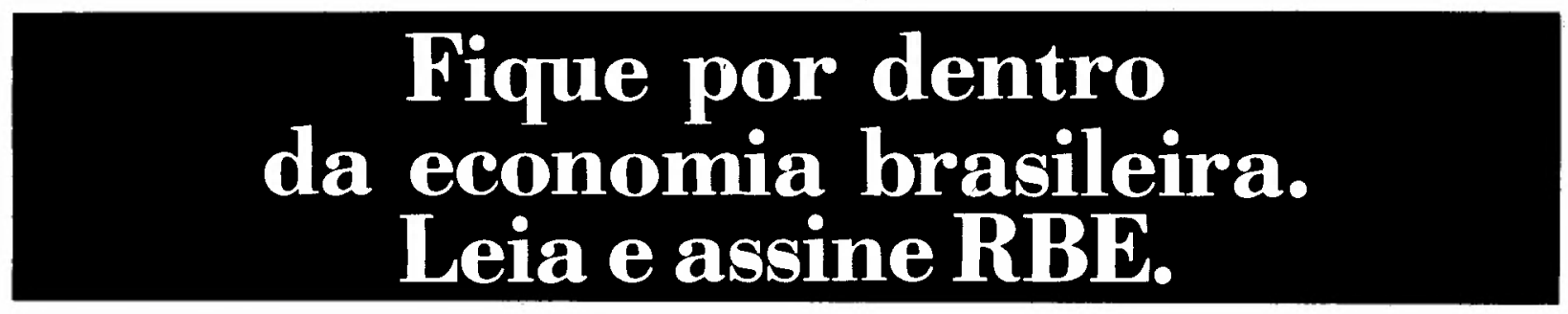

